\title{
Current status and clinical applicability of endobronchial ultrasound-guided transbronchial needle aspiration*
}

\author{
Estado atual e aplicabilidade clínica da punção aspirativa \\ por agulha guiada por ultrassom endobrônquico
}

\author{
Viviane Rossi Figueiredo, Márcia Jacomelli, Ascédio José Rodrigues, Mauro \\ Canzian, Paulo Francisco Guerreiro Cardoso, Fábio Biscegli Jatene
}

\begin{abstract}
Endobronchial ultrasound-guided transbronchial needle aspiration (EBUS-TBNA) has played a key role in the diagnosis of mediastinal, paratracheal, and peribronchial lesions, as well as in lymph node staging for lung cancer. Despite its minimally invasive character, EBUS-TBNA has demonstrated a diagnostic yield comparable with that of established surgical methods. It has therefore gained credibility and has become a routine procedure at various referral centers. A successful EBUS-TBNA procedure requires careful planning, which includes a thorough review of the radiological imaging and special care during specimen collection and preparation, as well as technical expertise, experience with the procedure itself, and knowledge of the potential complications inherent to the procedure. The most common indications for EBUS-TBNA include lymph node staging for lung cancer and the diagnostic investigation of mediastinal/hilar masses and lymph node enlargement. Recently, tumor biomarkers in malignant samples collected during the EBUS-TBNA procedure have begun to be identified, and this molecular analysis has proven to be absolutely feasible. The EBUS-TBNA procedure has yet to be included on the Brazilian Medical Association list of medical procedures approved for reimbursement. The EBUS-TBNA procedure has shown to be a safe and accurate tool for lung cancer staging/restaging, as well as for the diagnosis of mediastinal, paratracheal, and peribronchial lesions/lymph node enlargement.
\end{abstract}

Keywords: Endoscopic ultrasound-guided fine needle aspiration; Lung neoplasms; Neoplasm staging.

\section{Resumo}

Endobronchial ultrasound-guided transbronchial needle aspiration (EBUS-TBNA, punção aspirativa por agulha guiada por ultrassom endobrônquico) tem desempenhado um papel fundamental no diagnóstico de lesões mediastinais, paratraqueais e peribrônquicas, assim como no estadiamento linfonodal da neoplasia pulmonar. Por se tratar de exame endoscópico minimamente invasivo cujo rendimento diagnóstico tem se mostrado comparável aos métodos cirúrgicos estabelecidos, o procedimento de EBUS-TBNA ganhou espaço rapidamente e já se encontra integrado à rotina de investigação em serviços de referência. Para a realização de EBUSTBNA, é importante o planejamento prévio ao procedimento, que deve incluir uma análise minuciosa dos exames radiológicos e cuidado especial com a coleta e preparo do material, além do domínio da técnica e conhecimento de eventuais complicações inerentes ao procedimento. As principais indicações para a realização de EBUS-TBNA são o estadiamento linfonodal da neoplasia pulmonar e a investigação diagnóstica de massas e linfonodomegalias mediastinais ou hilares. Recentemente, iniciou-se a identificação de biomarcadores tumorais em amostras neoplásicas; essa análise molecular no material coletado durante o procedimento de EBUS-TBNA provou ser totalmente possível. Até o momento, o procedimento de EBUS-TBNA não consta nas tabelas de procedimentos médicos da Associação Médica Brasileira. 0 procedimento de EBUS-TBNA tem se mostrado seguro e eficaz no estadiamento e reestadiamento de neoplasia de pulmão e no esclarecimento diagnóstico de lesões ou linfonodomegalias mediastinais, paratraqueais e peribrônquicas.

Descritores: Biópsia por agulha fina; Neoplasias pulmonares; Estadiamento de neoplasias.

\footnotetext{
* Study carried out in the Department of Respiratory Endoscopy, Division of Thoracic Surgery, Instituto do Coração, Hospital das Clínicas da Faculdade de Medicina da Universidade de São Paulo - InCor/HC-FMUSP, Heart Institute/University of São Paulo School of Medicine Hospital das Clínicas - São Paulo, Brazil.

Correspondence to: Viviane Rossi Figueiredo. Serviço de Endoscopia Respiratória, Instituto do Coração, Avenida Dr. Enéas de Carvalho Aguiar, 44, Bloco 1, 7º Andar, Cerqueira César, CEP 05403-900, São Paulo, SP, Brasil.

Tel. 5511 2661-5612. E-mail: vivianerossifigueiredo@gmail.com

Financial support: None.
}

Submitted: 7 December 2012. Accepted, after review: 10 January 2013. 


\section{Introduction}

Flexible fiberoptic bronchoscopy plays a welldefined role in the diagnostic approach to lung masses and nodules, as well as in aspiration of mediastinal lesions and enlarged mediastinal lymph nodes. Although imaging tests such as chest CT and positron emission tomography combined with CT (PET/CT) can demonstrate the presence of lesions in the lungs or mediastinum, in most cases, cell or tissue sample collection is required to define the therapeutic approach.

During flexible fiberoptic bronchoscopy, endobronchial biopsy (EBB) and cytology brush of endoscopically visible lesions can be performed, as can (fluoroscopically or non-fluoroscopically guided) transbronchial biopsy (TBB) of parenchymal lesions and fine needle aspiration of mediastinal lesions and enlarged subcarinal lymph nodes. ${ }^{(1)}$

In a review of studies between 1971 and 2004, the American College of Chest Physicians observed that the overall diagnostic sensitivity of conventional bronchoscopy in lung cancer was, respectively, 88\% (range, 67-97\%) and 78\% (range, $36-88 \%$ ) for central and peripheral carcinoma. ${ }^{(2)}$

Each sample collection procedure has specific efficacy. The diagnostic yield of TBB alone in lung cancer ranges from 25\% to 58\% for nodules smaller than $2 \mathrm{~cm}$, increasing to $60-83 \%$ for nodules greater than $2 \mathrm{~cm} .{ }^{(3)}$ Likewise, the diagnostic yield of fine needle aspiration of mediastinal masses or lymph nodes will vary according to lesion size. The yield will be higher if there is bulging of the tracheobronchial tree or thickening of the carina and interlobular septa. ${ }^{(4)}$

New equipment and advanced technologies have been developed with the aim of improving the efficacy of bronchoscopic methods in the diagnosis of diseases of the lung and mediastinum. In this context, electromagnetic navigation and endobronchial ultrasound-guide sheath-or radial endobronchial ultrasound-have been developed to guide biopsies of peripheral nodules, whereas endobronchial ultrasound-guided transbronchial needle aspiration (EBUS-TBNA) is used in the diagnostic approach to the mediastinum and in lung cancer staging. Among these new methods, EBUS-TBNA has played a key role in the diagnosis of mediastinal, paratracheal, and peribronchial lesions, as well as in lymph node staging for lung cancer. Despite its minimally invasive character, EBUS-TBNA has demonstrated a diagnostic yield comparable with that of established surgical methods. ${ }^{(5)}$ It has therefore gained credibility and has become a routine procedure at various referral centers. The experience of implementing EBUS-TBNA in Brazil has brought to light some difficulties and peculiarities that merit discussion.

The objective of this review article was to describe EBUS-TBNA, the equipment used, the indications for the procedure, the technique for performing the procedure, and recent results.

\section{The EBUS-TBNA system}

In the last decade, EBUS systems, which allow needle aspiration, were developed, the differences from one to another being small.

The following are currently available in Brazil:

- BF-UC180F (Olympus Medical Systems, Tokyo, Japan), used with an Olympus EU-ME1 ultrasound processor or a ProSound Alpha 5 ultrasound processor (Aloka, Tokyo, Japan).

- EB-530US (Fujifilm Corporation, Tokyo, Japan), used with a Fujinon SU-8000 processor (Fujifilm Corporation).

As of 2013, the EB-1970UK (Pentax Medical Company, Montvale, NJ, USA), used with a Hitachi EUB-5500 ultrasound processor (Hitachi Medical Corporation, Kashiwa, Japan), will also be available in Brazil.

The system is dedicated for EBUS-TBNA, having a distal diameter of 6.3-6.9 mm (depending on the brand) and a 2-mm working channel capable of accommodating a $19 \mathrm{G}$ or $22 \mathrm{G}$ needle. The bronchoscopic view is oblique $\left(35^{\circ}-45^{\circ}\right)$ rather than frontal. Imaging can be achieved by videobronchoscopy or can be hybrid, with optical fiber transmission to the imaging sensor, which is located at the proximal end of the device.

The device has a convex ultrasound transducer (probe) integrated into the distal end, with a $60^{\circ}$ scanning angle. The systems provide different frequencies (5-12 MHz), there being variation among the brands available. Because lower frequencies translate to greater tissue scanning depth, the use of higher frequencies results in better image quality at more superficial layers. The Doppler function of the system allows identification of vascular structures, providing greater safety during aspiration of mediastinal lesions or enlarged mediastinal lymph nodes. The picture-in-picture feature of the bronchoscope processor allows the bronchoscopic and ultrasound images to be displayed side by side on the same screen. ${ }^{(6)}$ 
The probe located at the distal end of the system should be inserted into a latex balloon, and, during the procedure, this balloon should be inflated with distilled water at the time of ultrasound visualization of the structure that will be aspirated (Figures 1 and 2).

An EBUS-TBNA needle available in Brazil is dedicated (22G), disposable, and compatible with the system used, as well as having grooves in the distal end, which allows its visualization on ultrasound. Together with the needle, there is a vacuum syringe and a dedicated valve that connects the needle to the working channel of the EBUS system. ${ }^{(6)}$

\section{Procedure for performing EBUS-TBNA}

\section{Planning}

Regardless of the purpose of the procedure, it is essential that radiological (CT and/or PET/ CT) findings be analyzed in detail. The aspiration sites and their sequence should be defined before the beginning of the procedure.

In lymph node staging ( $\mathrm{N}$-staging) for lung cancer, systematizing the sequence is extremely important, since, in most centers where EBUSTBNA is part of routine care, a single needle is used for the entire procedure. ${ }^{(6)}$

The sequence of aspiration sites should begin with the lymph node stations located furthest from the tumor (N3 stations), followed by those located closest to the tumor (N1). When the primary tumor has not yet been histologically diagnosed and is accessible to aspiration, this tumor should be aspirated last in the sequence. Therefore, the sequence of aspiration sites should be maintained to prevent the neoplastic cells present in the needle from producing false-positive results at stations located furthest from the tumor. ${ }^{(6,7)}$

\section{Technique for performing EBUS-TBNA}

The procedure should be performed in the operating room or in the outpatient bronchoscopy room. In all cases, it is necessary that there be a suitable environment for performing bronchoscopic examinations as well as special furniture, with space for the medical and paramedical staff to move around. The room should be equipped with

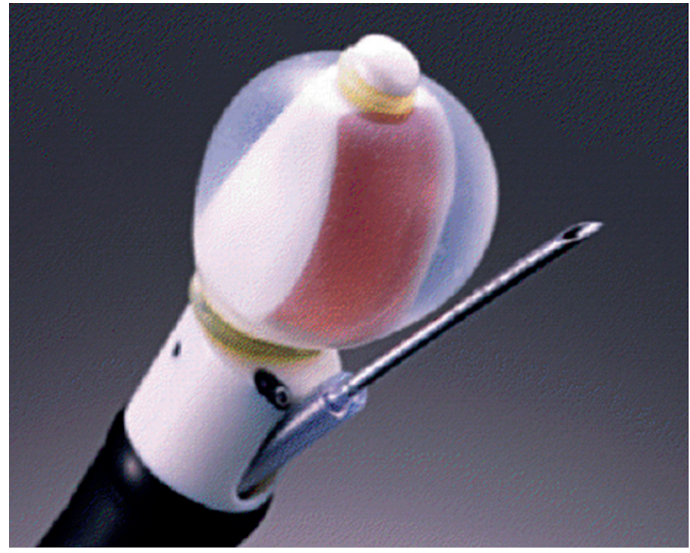

Figure 1 - Olympus echo-bronchoscope. Courtesy of Olympus Medical Systems.

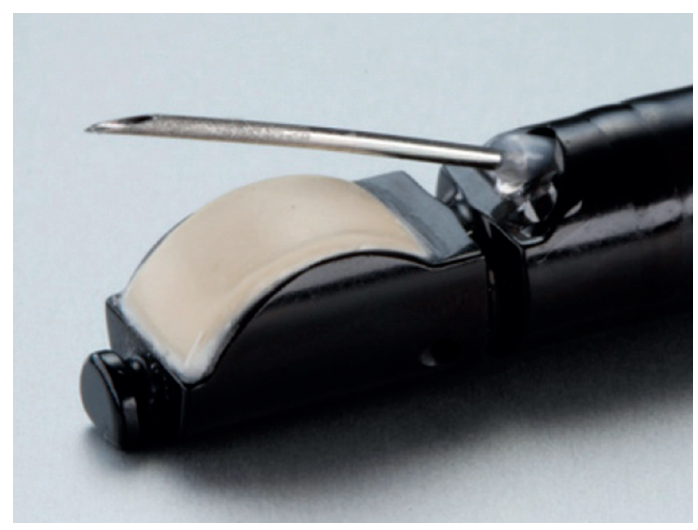

Figure 2 - Pentax echo-bronchoscope. Courtesy of Pentax Medical Company.

a mobile anesthesia apparatus and emergency supplies.

If possible, the EBUS-TBNA procedure should be preceded by conventional bronchoscopy in order to evaluate the entire respiratory tree, and aspiration of the site of an intraluminal lesion, which could produce false-positive results because of the presence of neoplastic cells in the aspiration pathway, should be avoided. ${ }^{(8)}$

The preparation of the system includes connecting the ultrasound probe to a latex balloon and testing the balloon by inflating it with distilled water, removing any air bubbles that are detrimental to providing the ultrasound window. The preparation of the examination table includes topical anesthesia supplies, an EBUS-TBNA needle, a vacuum syringe, cytology slides, and vials for embedded cell blocks.

The EBUS-TBNA procedure can be performed under general anesthesia or under sedation, similarly to what is done in conventional 
bronchoscopy. ${ }^{(9-12)}$ Topical anesthesia should be performed with $1 \%$ or $2 \%$ lidocaine. Regardless of whether the procedure is performed under general anesthesia or under sedation, the EBUS system should be introduced orally, given that its diameter prevents it from being introduced through the nasal cavity. ${ }^{(9,10,12)}$

The device should be passed through the larynx with caution, given that the bronchoscopic view is oblique and the ultrasound probe is located posteriorly to that view. Subsequently, ultrasound imaging of the lesion that will be diagnosed or of the first lymph node station that will be aspirated should be performed. After the tip of the device touches the tracheobronchial wall, the balloon should be inflated with distilled water so that the ultrasound probe is flat against the tracheal or bronchial wall, and the best ultrasound window to the lesion or lymph node should be found before aspiration. A 3- or 4-cm ultrasound depth is sufficient for the purpose of the examination. At this point, the gain, contrast, and brightness of the ultrasound image can be adjusted to obtain the highest resolution image of the lesion or structure. Doppler is recommended to differentiate between solid structures (lymph node or tumor) and vascular structures (Figure 3). ${ }^{(6)}$

In order to locate the hilar and mediastinal lymph node stations, it is necessary to know the anatomical landmarks between the tracheobronchial tree structures and the mediastinum, as well as the position of these lymph node stations that will be mapped. The lymph node map described by Yasufuku et al. is a useful tool. ${ }^{(13)}$

For lung cancer staging, it is recommended that there be a systematic approach to mediastinal and hilar lymph nodes. One technique involves ultrasound mapping of all accessible lymph nodes, with aspiration being performed only after mapping is complete. Thus, priority is given to aspiration of lymph nodes with a higher index of suspicion for malignancy, and these lymph nodes consequently have a significant impact on staging and on change of management. ${ }^{(10)}$ Another technique is performing aspiration simultaneously with mapping, choosing lymph nodes with characteristics suggestive of malignancy. ${ }^{(14)}$ In addition, any lymph node greater than $5 \mathrm{~mm}$ in diameter that is found during the procedure can be aspirated, and the sequence going from N3 stations to N1 stations should be respected. ${ }^{(15)}$

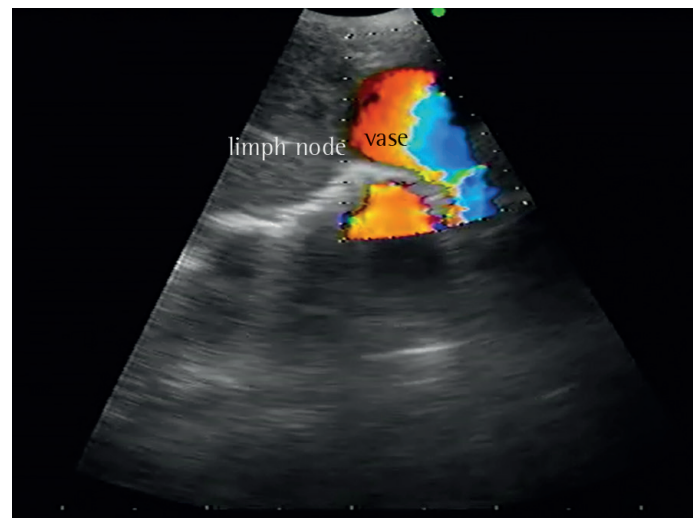

Figure 3 - Doppler ultrasound image of a lymph node and a vessel. Courtesy of the Department of Bronchoscopy, Heart Institute, University of São Paulo School of Medicine Hospital das Clínicas.

In order to give priority to aspiration of lymph nodes suspected of harboring malignancy, ultrasound morphology has been studied to identify the predictors for metastasis. Fujiwara et al. investigated the size of lymph nodes (greater or smaller than $10 \mathrm{~mm}$ in the shortest axis), their shape (round or oval), their border definition, and their echogenicity (heterogeneous or homogeneous), as well as the presence or absence of the hilar lymph node and the presence or absence of necrosis. The accuracy of each studied parameter in predicting metastasis ranged from $63.8 \%$ to $86.0 \%$. A multivariate analysis revealed that a round shape, well-defined borders, heterogeneous echogenicity, and the presence of necrosis were predictors for lymph node metastasis. At least one of these four characteristics was present in the lymph nodes found to be metastatic, whereas none of them were present in 96\% of the lymph nodes found to be benign. ${ }^{(14)}$

Recently, the vascular image patterns of lymph nodes were investigated by Nakajima et al. ${ }^{(16)}$ The image findings were graded as follows: grade 0 , no vessels within the lymph nodes; grade 1 , small vessels running toward the hilum; grade 11, punctiform vessels or small vessels found as a long strip of a curve; and grade 111, various twisted vessels with different diameters. When the authors defined grades 0 and 1 as benign and grades 11 and 111 as malignant, the sensitivity, specificity, and diagnostic accuracy were 87.7\%, $69.6 \%$, and $78.8 \%$, respectively.

Another important aspect concerns the diameter of lymph nodes. Unlike what is observed for 
imaging methods used in radiological staging of lung cancer, EBUS-TBNA findings have demonstrated that lymph nodes measuring less than $10 \mathrm{~mm}$ in diameter on CT scans can be metastatic, even if there is no evidence of uptake on PET/CT scans. The EBUS-TBNA procedure can detect metastasis in lymph nodes measuring between 5 and $10 \mathrm{~mm}$ with a sensitivity of $89 \%$ and a negative predictive value (NPV) of $98.9 \% .^{(17)}$

\section{Sample collection}

Wang needle $(21 \mathrm{G})$ transtracheal/transbronchial aspiration is still often used in conventional bronchoscopy because of its ease of use, safety, and low cost; however, up to $43 \%$ of the collected samples are unsatisfactory for diagnosis. ${ }^{(18)}$ Available in Brazil, EBUS needles measure 22G in diameter, are provided with a protective sheath, have an exposure of approximately $4 \mathrm{~cm}$, and have two to three safety locks to reduce the risk of accidents related to aspiration (vessels and other mediastinal structures) and the risk of perforation of the working channel of the device. The needle set includes a dedicated valve that fits into the working channel port of the device, thereby making it possible to connect the needle to the EBUS equipment. Once the needle is introduced into the working channel, it should be pushed until it fully fits into the valve connected to the device and is locked. The sheath should remain exposed until it is seen bronchoscopically, and only then can the safety lock of the needle be released. The needle should be advanced through the tracheobronchial wall in order to aspirate paratracheal or peribronchial lymph nodes or lesions (Figure 4).

Regarding the aspiration technique, the literature suggests at least three aspirations per lymph node or lesion, with various passes (10-15 needle movements) being performed per aspiration in order to obtain sufficient material in the absence of an on-site cytopathologist. Yasufuku et al. recommend that the number of aspirations per lymph node should be limited to five, even when there is an on-site cytopathologist. ${ }^{(6)}$ The same authors believe that, if no adequate material is obtained in any of the aspirations, this material should be considered inconclusive for diagnosis.

In clinical practice, we have observed that the number of passes performed per aspiration can be adapted to suit each individual case. Aspiration of highly vascularized lymph nodes often results in samples replete with blood, which makes it difficult for the cytopathologist to analyze the material. In such cases, performing few passes (from 3 to 7 ) per aspiration is usually sufficient to prevent the needle lumen from being filled with blood. Another particular case is aspiration of hilar and mediastinal lymph nodes after chemotherapy. In such cases of suspected mediastinal recurrence of cancer or in mediastinal restaging after neoadjuvant therapy, samples should be collected from the lymph node periphery, as required in mediastinoscopy/thoracoscopy, thereby avoiding the central region of the lymph node, which usually has the largest area of necrosis.

Another interesting observation concerns how the needle is inserted into the lymph node in order to obtain histological rather than cytological samples. To that end, once the needle is within the lymph node, and after the guide wire is removed, the vacuum syringe is connected and the passes are performed quickly and forcefully (jab), thereby aspirating lymph node fragments. ${ }^{(6)}$

For subsequent cytological and/or histological analysis, the samples should be placed on slides (dry slides or slides fixed in absolute alcohol) and in formalin (cell block). When infection (such as tuberculosis or fungal infection) is suspected, some of the samples should be sent for microbiological analysis (in sterile saline for tests and culture for bacteria, fungi, and AFB). ${ }^{(8,12)}$

\section{Preparation of the collected samples}

Proper preparation of specimens for cytology is essential for ensuring that EBUS-TBNA has a

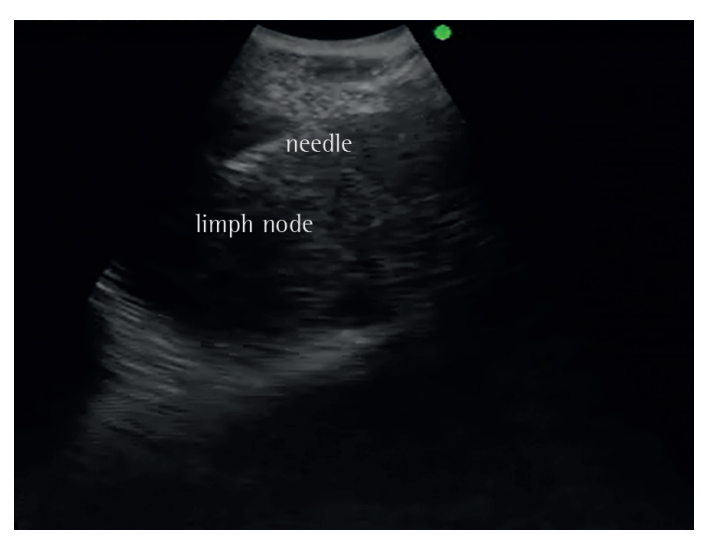

Figure 4 - Ultrasound image from lymph node fine needle aspiration. Courtesy of the Department of Bronchoscopy, Heart Institute, University of São Paulo School of Medicine Hospital das Clínicas. 
good diagnostic yield. Usually, aspiration samples consist of a liquid phase (a fluid or thick drop, with or without blood), a semisolid phase, and a solid phase.

After the fluid or thick drop is placed on the cytology slide, another slide or a coverslip is placed against the first slide at an angle of $45^{\circ}$ or is placed horizontally on top of it and is gently slid along the base slide until it reaches the opposite end, causing the liquid sample to spread uniformly (Figure 5). For semisolid samples, the procedure is similar, and clots and small solid fragments remaining at the edge of the drop should be gently compressed or removed from the slide with a needle and placed in fixative for paraffin-embedded cell-block analysis.

Solid samples are placed in a vial containing fixative and are then centrifuged, concentrating the cellular material that was in suspension after the syringe and needle are washed. The fragments as well as the resulting sediment (pellet) are embedded in paraffin as "mini biopsies" (cell block; Figure 6), making it possible to obtain histological sections that will examined using histochemistry (routine staining, H\&E, or specific staining) or immunohistochemistry (Figure 7). ${ }^{(8)}$

The presence of an on-site physician or cytotechnologist is important for determining whether or not the material is adequate and for screening the samples in complementary analyses (immunohistochemical analysis, gene mutation determination, culture, etc.). ${ }^{(19)}$ Some studies, however, have found no improvement in the diagnostic yield of EBUS-TBNA resulting from the presence of an on-site cytopathologist, which can be standardized after all staff involved in the procedure have overcome the learning curve. ${ }^{(20)}$

In our initial experience with 50 procedures, we observed that inadequate material was collected in approximately $26 \%$ of the aspirations, ${ }^{(21)}$ compared with 13\% currently (unpublished data).

\section{Indications for EBUS-TBNA}

The most common indications for EBUS-TBNA include lymph node staging for lung cancer and the diagnostic investigation of mediastinal/hilar masses and lymph node enlargement.

\section{Lung cancer staging}

The current recommendations for invasive mediastinal staging by sampling five lymph node stations include all cases of diagnosed lung cancer without distant metastasis, with the exception of cases classified as stage la (clinical/radiological staging) with negative PET/CT findings in the mediastinum. ${ }^{(22)}$

Various methods have been used for lung cancer staging, assisting in therapeutic decision making and in patient prognosis. Both $\mathrm{CT}$ and $\mathrm{PET} / \mathrm{CT}$ are

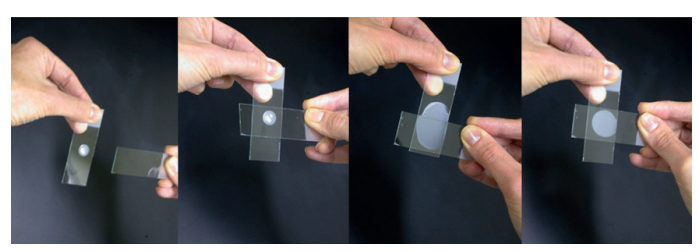

Figure 5 - Cytology slide preparation. Courtesy of Dr. Cristina Mitteldorf.

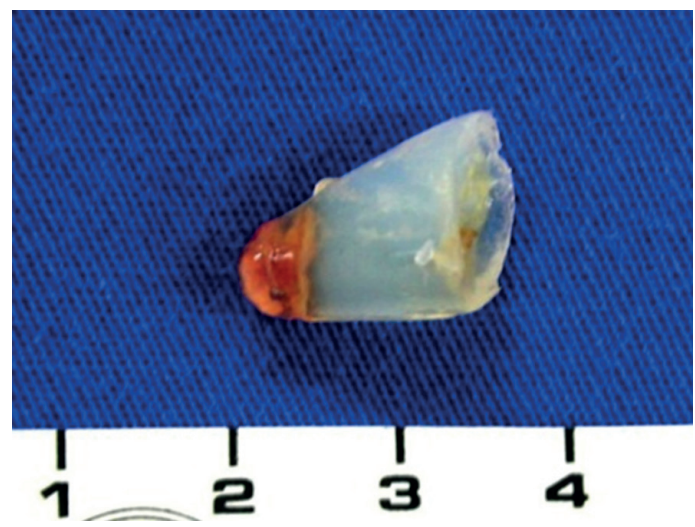

Figure 6 - Paraffin block containing lymph node aspirate. Courtesy of Dr. Cristina Mitteldorf.

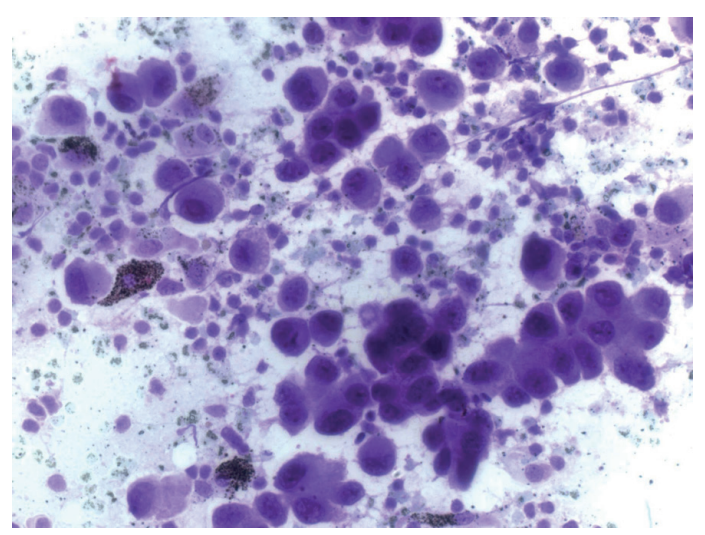

Figure 7 - Photomicrograph of a cytology slide from a lymph node aspirate, indicating adenocarcinoma (thionine; magnification, $\times 400$ ). Courtesy of the Anatomic Pathology Laboratory, Heart Institute, University of São Paulo School of Medicine Hospital das Clínicas. 
widely used for this purpose. A prospective study involving 102 patients compared the accuracy of CT, PET/CT, and EBUS-TBNA for the detection of lymph node metastasis in lung cancer. With the exception of the patients with extensive N2 disease (bulky disease or involvement of multiple ipsilateral lymph node stations) and N3 disease diagnosed by EBUS-TBNA, the other patients underwent lobectomy with lymph node dissection, making it possible to confirm the EBUS-TBNA cytohistological findings. The diagnostic accuracy of CT, PET/CT, and EBUS-TBNA was 60.6\%, 72.5\%, and $98.0 \%$, respectively, the differences between the groups being significant $(p<0.0001)$. $^{(23)}$

Herth et al. have questioned the CT and PET/CT criteria used for the detection of lymph node metastasis. In their study, 97 patients with confirmed non-small cell lung cancer and with no lymph node changes suggestive of metastasis on CT or PET/CT scans underwent EBUS-TBNA. lymph nodes measuring $5-10 \mathrm{~mm}$ in diameter at stations 2, 4, 7, 10, and 11 were aspirated, and, subsequently, all of the patients underwent surgical staging. Lymph node metastasis was detected at surgical staging in 9 patients. In 8 of those patients, lymph node metastasis had been identified by EBUS-TBNA. The sensitivity of EBUS-TBNA for the detection of mediastinal metastasis was 89\%, and its specificity and NPV were $100 \%$ and 99\%, respectively. ${ }^{(17)}$

Another widely discussed issue is the value of EBUS-TBNA when compared with that of mediastinoscopy in lymph node staging for lung cancer. A prospective study included 59 patients and compared the diagnostic yield of EBUSTBNA with that of cervical mediastinoscopy for the detection of lymph node metastasis in lung cancer. Although, in terms of the overall yield per lymph node, the EBUS-TBNA results were better than were those of mediastinoscopy (98\% vs. $78 \% ; p=0.007$ ), there were no significant differences between the methods when the evaluation was performed by patient (sensitivity, 87\%; specificity, 100\%; and NPV, 78\% for EBUSTBNA vs. sensitivity, 68\%; specificity, 100\%; and NPV, 59\% for mediastinoscopy). ${ }^{(24)}$

More recently, another prospective study comparing EBUS-TBNA and mediastinoscopy demonstrated that the results of both methods were similar in terms of mediastinal staging in 91\% of the patients studied. The sensitivity, NPV, and diagnostic accuracy were $81 \%, 91 \%$, and
93\%, respectively, for EBUS-TBNA, compared with 79\%, 90\%, and 93\%, respectively, for mediastinoscopy, and there were no statistically significant differences between the methods. ${ }^{(5)}$

\section{Lung cancer restaging after neoadjuvant therapy}

For lung cancer restaging after neoadjuvant therapy, it is necessary to identify the patients who demonstrate reduction in staging and who will therefore potentially benefit from surgical treatment. There are many response criteria, most of which are based on imaging methods.

A multicenter study involving 124 patients with stage 11la (N2) lung cancer observed that EBUS-TBNA identified persistent nodal metastases (N2) in $72 \%$ of the patients. In the remaining patients (without lymph node metastasis) who underwent thoracotomy, the sensitivity, specificity, positive predictive value (PPV), NPV, and diagnostic accuracy of EBUS-TBNA were 76\%, 100\%, 100\%, $20 \%$, and $77 \%$, respectively. Those authors believe that the low NPV was due to sampling error rather than to detection error. Therefore, they recommend that, in cases of restaging by EBUSTBNA, negative findings be confirmed by surgical restaging before thoracotomy. ${ }^{(25)}$

A prospective study included 61 patients with stage 11la and $11 \mathrm{lb}$ lung cancer as determined by EBUS-TBNA after neoadjuvant chemotherapy, presenting with stable lymph nodes or with partial response after chemotherapy as demonstrated by chest $\mathrm{CT}$ scans, and whose clinical condition allowed surgical resection. All of them underwent restaging by EBUS-TBNA. The patients with negative EBUS-TBNA results for cancer underwent transcervical extended mediastinal lymphadenectomy for histological confirmation. Lymph node metastasis was detected by EBUSTBNA in $18(30 \%)$ of the 61 patients and in 22 (26\%) of the 85 of the aspirated nodes. Metastatic lymph nodes were identified in $9(15 \%)$ of the 43 patients who underwent transcervical extended mediastinal lymphadenectomy-in 7 patients, at lymph node stations accessible by EBUS-TBNA (stations 2R, 4R, and 7), and, in 2 patients, at a station not accessible by EBUS-TBNA (station 5). The sensitivity, specificity, accuracy, PPV, and NPV of EBUS-TBNA for the detection of lymph node metastasis in restaging were 67\%,86\%,80\%, 91\% e 78\%, respectively. No complications of EBUSTBNA were observed. The authors concluded that 
EBUS-TBNA is an effective and safe method for mediastinal restaging of patients with (non-small cell) lung cancer and that surgical restaging of the mediastinum might not be mandatory in such cases. ${ }^{(26)}$

\section{Investigation of mediastinal tumors}

Various studies have demonstrated the good diagnostic yield of EBUS-TBNA in undiagnosed mediastinal or peribronchial lesions, whether they are benign or malignant. Yasufuku et al. studied 140 patients with mediastinal tumors in the absence of lung cancer or extrapulmonary cancer. The EBUS-TBNA was diagnostic in 93.6\% of all (benign and malignant) disorders. ${ }^{(27)}$

A study involving 60 patients observed that EBUS-TBNA was able to diagnose mediastinal lesions with a sensitivity, specificity, and accuracy of 95\%, 100\%, and 98\%, respectively. ${ }^{(28)}$ In assessing the potential accuracy of EBUS-TBNA in cases of suspected thymoma, a retrospective analysis of 1,458 EBUS-TBNA procedures found 4 cases of thymic cancer, 3 of which were cases of type B thymoma (one each of B1, B2 and B3 subtypes, all of which were diagnosed by cytology) and 1 of which was a case of thymic carcinoma diagnosed by immunocytochemistry analysis of cell blocks and flow cytometry. ${ }^{(29)}$

\section{Investigation of lymph node enlargement from other causes}

The EBUS-TBNA procedure has been used in the investigation of mediastinal and hilar lymph node enlargement in benign and malignant non-pulmonary disease. A retrospective study of the usefulness of EBUS-TBNA for the diagnostic investigation of mediastinal and hilar lymph node enlargement observed that, in 95 of 120 patients, the material collected was diagnostic. The diagnoses included lymphoid hyperplasia, granulomatous lymphadenitis, Hodgkin lymphoma, non-Hodgkin lymphoma, etc. The study concluded that EBUS-TBNA provides sufficient sample for diagnosis and classification of most disorders in patients with mediastinal lymphadenopathy. (30) Another similar study concluded that, in 31 of 33 patients investigated for mediastinal and hilar lymph node enlargement who underwent EBUS-TBNA, adequate material was obtained for diagnosis: reactive lymph nodes, in 8; granulomatous inflammation, in 11; lymphoma, in 8; suspected non-Hodgkin lymphoma, in 2; and presence of atypical cells, in $2 .^{(31)}$

\section{Lymphoma}

Kennedy et al. performed a retrospective review of 25 patients with mediastinal lymph node enlargement referred for EBUS-TBNA in whom lymphoma was suspected. Adequate samples for diagnosis were observed in 24 patients (96\%), and there were no complications of the procedure. Lymphoma was identified in 10 patients, benign disease was identified in 14 patients, and there was one false negative for lymphoma (lymphoma prevalence: 11/25, 44\%). Follow-up over approximately 10 months confirmed stable or regressive lymph node enlargement in all 14 patients without a lymphoma diagnosis, consistent with a benign diagnosis. The sensitivity, specificity, PPV, and NPV of EBUS-TBNA for the diagnosis of lymphoma was $90.9 \%, 100.0 \%, 100.0 \%$, and $92.9 \%$, respectively. ${ }^{(32)}$

\section{Sarcoidosis}

Among benign mediastinal and hilar lymphadenopathies, stage 1 and stage 11 sarcoidosis can be diagnosed by EBUS-TBNA. A prospective multicenter study evaluated 65 patients with suspected sarcoidosis (stage 1 and 11 in 74\% and 26\%, respectively) and with hilar/ mediastinal adenopathy on CT. Patients with suspected malignancy, those who had been previously diagnosed with sarcoidosis, and those in whom no granulomas were found in the aspirates were excluded. The selected patients underwent diagnostic surgical procedures and were followed up clinically. A definitive diagnosis of sarcoidosis was made in 61 patients (93.8\%). Of the remaining 4 patients, 1 was diagnosed with Wegener's granulomatosis and 3 had no definitive diagnosis. In 56 (91.8\%) of the 61 patients with a final diagnosis of sarcoidosis, noncaseating epithelioid cell granulomas were found in the aspirates. No complications were reported, demonstrating that EBUS-TBNA is safe and has a high diagnostic yield. ${ }^{(8)}$ Navani et al. evaluated 40 patients suspected to have stage 1 or stage 11 sarcoidosis on the basis of the clinical details and radiological findings. Of those 40 patients, 39 underwent EBUS-TBNA and conventional bronchoscopy with TBB, EBB, and blind transcarinal aspiration. Lymph node samples 
were obtained by mediastinoscopy in patients in whom the two methods were inconclusive. In the patients diagnosed with sarcoidosis, the sensitivity of EBUS-TBNA was 85\%, compared with a sensitivity of 35\% for conventional bronchoscopy with TBB, EBB, and blind transcarinal aspiration. When the two methods were combined, the sensitivity increased to $93 \% .^{(33)}$

\section{Mediastinal lymph node tuberculosis}

Tuberculosis should be considered in the differential diagnosis of mediastinal and hilar lymph node enlargement, even in the absence of pulmonary changes. A multicenter study included 156 patients with mediastinal adenopathy as demonstrated by chest CT scans and excluded those with pulmonary or extrathoracic tuberculosis. The EBUS-TBNA was diagnostic in 94\% of the cases, and culture was positive in $47 \%,{ }^{(12)}$ including the diagnosis of multidrug-resistant tuberculosis in 8 cases. Aspirate histology consistent with lymph node tuberculosis was observed in $86 \%$ of the cases.

\section{Analysis of the molecular profile of lung cancer}

Molecular analysis of neoplastic samples is essential in the identification of tumor biomarkers. The objective is to identify patients who will respond better to certain types of chemotherapeutic agents (target therapy). Cytological and histological specimens acquired by EBUS-TBNA have been used for the analysis of these tumor markers.

In a study involving 43 patients with lung adenocarcinoma who underwent EBUS-TBNA for staging, the lymph node samples collected were analyzed for epidermal growth factor receptor (EGFR) mutation. The cell blocks were positive for the EGFR mutation in 11 cases, all of which were confirmed by direct sequencing. In conclusion, the EGFR mutation is easily detected in specimens acquired by EBUS-TBNA. ${ }^{(34)}$ Another study, also involving 43 patients with non-small cell lung cancer, analyzed some markers (KRAS, EGFR, BRAF, and $P I K_{3} C A$ mutation) in the specimens acquired by EBUS-TBNA and by endoscopic ultrasoundguided fine needle aspiration and found that there was complete concordance between the results obtained by the analysis of tumor markers performed on the cytological specimens acquired by the two aspiration methods and those obtained on surgical histological specimens. ${ }^{(35)}$ Those authors concluded that, if properly prepared, specimens acquired by EBUS-TBNA enable the analysis of genetic markers of lung cancer.

\section{Complications of EBUS-TBNA}

$A$ recent meta-analysis evaluated the effectiveness of EBUS-TBNA in lung cancer staging. Among the 11 included studies, involving a total of 1,299 patients, only one major complication was observed $(0.07 \%)$ in a patient with hypoxemia and severe COPD, this complication being followed by pneumothorax, which required drainage. ${ }^{(36)}$

In a group of 156 patients investigated for mediastinal lymph node enlargement, 1 patient presented with septicemia (group $\mathrm{G} \beta$-hemolytic streptococcus) two days following EBUS-TBNA. There were no complications during the procedures. (12) This infection suggests that intratracheal material entered the mediastinum. This mechanism had been described in a study involving 45 patients investigated for bacteremia following EBUS-TBNA (7\% of the patients; incidence comparable to that following conventional bronchoscopy). ${ }^{(37)}$

In a recent review of 14 studies involving 1,627 patients who underwent EBUS-TBNA, no major complications during or following the procedure were reported. ${ }^{(38)}$

In our experience, we observed a single case of moderate endobronchial bleeding, controlled with local measures, during EBUS-TBNA in a group of 50 patients. ${ }^{(21)}$

\section{Costs and reimbursement}

To date in Brazil, there have been no studies of the costs of using EBUS-TBNA, nor have there been any studies comparing the EBUSTBNA procedure and mediastinoscopy in terms of costs. A recent study conducted in Great Britain observed that the overall cost of the EBUS-TBNA procedure was US $\$ 2,998$, which was lower than that of mediastinoscopy, which was US $\$ 5,115 . .^{(39)}$ A review article including U.S. data ${ }^{(40)}$ reported that the price of an EBUS bronchoscope, excluding bronchoscope processors and ultrasound processors, is approximately US\$44,800. Each EBUS-TBNA needle costs approximately US $\$ 90$.

These costs are not reproducible in Brazil.

This is due, in part, to the high import taxes on the equipment and the needles. Currently, in Brazil, the direct import price (free on board price, 
i.e., no shipping fees or import taxes) of an EBUS bronchoscope, excluding bronchoscope processors and ultrasound processors, is approximately US\$73,000. Each EBUS-TBNA needle costs approximately $\mathrm{R} \$ 1,200$ for purchase on the domestic market.

The EBUS-TBNA procedure has yet to be included on the Brazilian Medical Association list of medical procedures approved for reimbursement. This restricts the availability of the procedure to patients with private health insurance plans or to those treated at hospitals that subsidize the difference in the amount paid by the Brazilian Unified Health Care System for conventional bronchoscopy.

\section{Final considerations}

The EBUS-TBNA procedure is efficient in lung cancer staging/restaging, as well as in the diagnosis of mediastinal, paratracheal, and peribronchial lesions/lymph node enlargement.

A single EBUS-TBNA procedure can diagnose paratracheal and peribronchial lung cancer and can provide lymph node staging information at the same time, especially if performed in a planned, sequential, and standardized way.

In addition to enabling cytological diagnosis, proper preparation of aspirates can enable assessment of the material as cell blocks. This allows genetic analysis of tumor markers, as well as storage of material for future evaluation with new techniques.

The implementation of EBUS-TBNA in Brazil requires a restructuring of facilities, the purchase of equipment, and the training of the multidisciplinary medical team and the paramedical team. Successful implementation also requires changes in the approach to patients who will benefit from the procedure. Finally, in order to increase and ensure access to this technology at health care facilities in Brazil, the pricing policy for equipment, as well as for the respective accessories, must be revised.

\section{References}

1. Prakash UB, Offord KP, Stubbs SE. Bronchoscopy in North America: the ACCP survey. Chest. 1991;100(6):1668-75.

2. Rivera MP, Mehta AC; American College of Chest Physicians. Initial diagnosis of lung cancer: ACCP evidence-based clinical practice guidelines (2nd edition). Chest. 2007;132(3 Suppl):131S-148S.
3. Wang Memoli JS, Nietert PJ, Silvestri GA. Meta-analysis of guided bronchoscopy for the evaluation of the pulmonary nodule. Chest. 2012;142(2):385-93.

4. Dasgupta A, Mehta AC. Transbronchial needle aspiration. An underused diagnostic technique. Clin Chest Med. 1999;20(1):39-51.

5. Yasufuku K, Pierre A, Darling G, de Perrot M, Waddell $\mathrm{T}$, Johnston $\mathrm{M}$, et al. A prospective controlled trial of endobronchial ultrasound-guided transbronchial needle aspiration compared with mediastinoscopy for mediastinal lymph node staging of lung cancer. J Thorac Cardiovasc Surg. 2011;142(6):1393-400.

6. Yasufuku K, Chiyo M, Koh E, Moriya Y, lyoda A, Sekine $Y$, et al. Endobronchial ultrasound guided transbronchial needle aspiration for staging of lung cancer. Lung Cancer. 2005;50(3):347-54.

7. Rusch VW, Asamura H, Watanabe H, Giroux DJ, RamiPorta R, Goldstraw P, et al. The IASLC lung cancer staging project: a proposal for a new international lymph node map in the forthcoming seventh edition of the TNM classification for lung cancer. J Thorac Oncol. 2009;4(5):568-77.

8. Bolliger C, Mathur P, editors. Interventional Bronchoscopy. Basel: Karger; 2000.

9. Wong M, Yasufuku K, Nakajima T, Herth FJ, Sekine Y, Shibuya K, et al. Endobronchial ultrasound: new insight for the diagnosis of sarcoidosis. Eur Respir J. 2007;29(6):1182-6.

10. Nakajima T, Yasufuku K. The techniques of endobronchial ultrasound-guided transbronchial needle aspiration. Innovations (Phila). 2011;6(1):57-64.

11. Kurimoto N, Fielding D, Musani A, editors. Endobronchial ultrasonography. Chichester: Wiley-Blackwell; 2011.

12. Navani N, Molyneaux PL, Breen RA, Connell DW, Jepson A, Nankivell M, et al. Utility of endobronchial ultrasoundguided transbronchial needle aspiration in patients with tuberculous intrathoracic lymphadenopathy: a multicentre study. Thorax. 2011;66(10):889-93.

13. Yasufuku K. EBUS-TBNA bronchoscopy. In: Ernst A, Herth F, editors. Endobronchial Ultrasound: An Atlas and Practical Guide. New York: Springer; 2009. p. 119-44.

14. Fujiwara T, Yasufuku K, Nakajima T, Chiyo M, Yoshida S, Suzuki M, et al. The utility of sonographic features during endobronchial ultrasound-guided transbronchial needle aspiration for lymph node staging in patients with lung cancer: a standard endobronchial ultrasound image classification system. Chest. 2010;138(3):641-7.

15. Rice DC, Steliga MA, Stewart J, Eapen G, Jimenez CA, Lee $\mathrm{JH}$, et al. Endoscopic ultrasound-guided fine needle aspiration for staging of malignant pleural mesothelioma. Ann Thorac Surg. 2009;88(3):862-8; discussion 868-9.

16. Nakajima T, Anayama T, Shingyoji M, Kimura H, Yoshino 1, Yasufuku K. Vascular image patterns of lymph nodes for the prediction of metastatic disease during EBUSTBNA for mediastinal staging of lung cancer. J Thorac Oncol. 2012;7(6):1009-14.

17. Herth FJ, Eberhardt R, Krasnik M, Ernst A. Endobronchial ultrasound-guided transbronchial needle aspiration of lymph nodes in the radiologically and positron emission tomography-normal mediastinum in patients with lung cancer. Chest. 2008;133(4):887-91.

18. Lannes D, Monteiro AS, Toscano E, Cavalcanti A, Nascimento M, de Biasi P, et al. Transbronchial needle aspiration of hilar and mediastinal lymph nodes [Article in Portuguese]. Rev Port Pneumol. 2007;13(5):651-8. 
19. Monaco SE, Pantanowitz L, Khalbuss WE. Comparing endobronchial ultrasound-guided fine needle aspiration specimens with and without rapid on-site evaluation. Cytojournal. 2012;9:2.

20. Griffin AC, Schwartz LE, Baloch ZW. Utility of on-site evaluation of endobronchial ultrasound-guided transbronchial needle aspiration specimens. Cytojournal. 2011;8:20.

21. Tedde ML, Figueiredo VR, Terra RM, Minamoto H, Jatene FB. Endobronchial ultrasound-guided transbronchial needle aspiration in the diagnosis and staging of mediastinal lymphadenopathy: initial experience in Brazil. J Bras Pneumol. 2012;38(1):33-40.

22. Darling GE, Dickie AJ, Malthaner RA, Kennedy EB, Tey R. Invasive mediastinal staging of non-small-cell lung cancer: a clinical practice guideline. Curr Oncol. 2011;18(6):e304-10.

23. Yasufuku K, Nakajima T, Motoori K, Sekine Y, Shibuya K, Hiroshima K, et al. Comparison of endobronchial ultrasound, positron emission tomography, and CT for lymph node staging of lung cancer. Chest. 2006;130(3):710-8.

24. Ernst A, Anantham D, Eberhardt R, Krasnik M, Herth FJ. Diagnosis of mediastinal adenopathy-real-time endobronchial ultrasound guided needle aspiration versus mediastinoscopy. J Thorac Oncol. 2008;3(6):577-82.

25. Herth FJ, Annema JT, Eberhardt R, Yasufuku K, Ernst A, Krasnik M, et al. Endobronchial ultrasound with transbronchial needle aspiration for restaging the mediastinum in lung cancer. J Clin Oncol. 2008;26(20):3346-50.

26. Szlubowski A, Herth FJ, Soja J, Kołodziej M, Figura J, Cmiel A, et al. Endobronchial ultrasound-guided needle aspiration in non-small-cell lung cancer restaging verified by the transcervical bilateral extended mediastinal lymphadenectomy--a prospective study. Eur J Cardiothorac Surg. 2010;37(5):1180-4.

27. Yasufuku K, Nakajima T, Fujiwara T, Yoshino I, Keshavjee S. Utility of endobronchial ultrasound-guided transbronchial needle aspiration in the diagnosis of mediastinal masses of unknown etiology. Ann Thorac Surg. 2011;91(3):831-6.

28. Zhao H, Wang J, Zhou ZL, Li Y, Bu L, Yang F, et al. Application of endobronchial ultrasoundguided transbronchial needle aspiration in the diagnosis of mediastinal lesions. Chin Med J (Engl). 2011;124(23):3988-92.

29. Moonim MT, Breen R, Gill-Barman B, Santis G. Diagnosis and subclassification of thymoma by minimally invasive fine needle aspiration directed by endobronchial ultrasound: a review and discussion of four cases. Cytopathology. 2012;23(4):220-8.
30. Ko HM, da Cunha Santos G, Darling G, Pierre A, Yasufuku K, Boerner SL, et al. Diagnosis and subclassification of lymphomas and non-neoplastic lesions involving mediastinal lymph nodes using endobronchial ultrasoundguided transbronchial needle aspiration. Diagn Cytopathol. 2011. doi: 10.1002/dc.21741. [Epub ahead of print].

31. Marshall CB, Jacob B, Patel S, Sneige N, Jimenez CA, Morice RC, et al. The utility of endobronchial ultrasoundguided transbronchial needle aspiration biopsy in the diagnosis of mediastinal lymphoproliferative disorders. Cancer Cytopathol. 2011;119(2):118-26.

32. Kennedy MP, Jimenez CA, Bruzzi JF, Mhatre AD, Lei $X$, Giles FJ, et al. Endobronchial ultrasound-guided transbronchial needle aspiration in the diagnosis of lymphoma. Thorax. 2008;63(4):360-5.

33. Navani N, Booth HL, Kocjan G, Falzon M, Capitanio A, Brown JM, et al. Combination of endobronchial ultrasound-guided transbronchial needle aspiration with standard bronchoscopic techniques for the diagnosis of stage 1 and stage 11 pulmonary sarcoidosis. Respirology. 2011;16(3):467-72.

34. Nakajima T, Yasufuku K, Suzuki M, Hiroshima K, Kubo R, Mohammed S, et al. Assessment of epidermal growth factor receptor mutation by endobronchial ultrasound-guided transbronchial needle aspiration. Chest. 2007;132(2):597-602.

35. van Eijk R, Licht J, Schrumpf M, Talebian Yazdi M, Ruano D, Forte Gl, et al. Rapid KRAS, EGFR, BRAF and PIK3CA mutation analysis of fine needle aspirates from non-small-cell lung cancer using allele-specific qPCR. PLoS One. 2011;6(3):e17791.

36. Gu P, Zhao YZ, Jiang LY, Zhang W, Xin Y, Han BH. Endobronchial ultrasound-guided transbronchial needle aspiration for staging of lung cancer: a systematic review and meta-analysis. Eur J Cancer. 2009;45(8):1389-96.

37. Steinfort DP, Johnson DF, Irving LB. Incidence of bacteraemia following endobronchial ultrasoundguided transbronchial needle aspiration. Eur Respir J. 2010;36(1):28-32.

38. Varela-Lema L, Fernández-Villar A, Ruano-Ravina A. Effectiveness and safety of endobronchial ultrasoundtransbronchial needle aspiration: a systematic review. Eur Respir J. 2009;33(5):1156-64.

39. Navani N, Lawrence DR, Kolvekar S, Hayward M, McAsey D, Kocjan G, et al. Endobronchial ultrasoundguided transbronchial needle aspiration prevents mediastinoscopies in the diagnosis of isolated mediastinal lymphadenopathy: a prospective trial. Am J Respir Crit Care Med. 2012;186(3):255-60.

40. Sheski FD, Mathur PN. Endobronchial ultrasound. Chest. 2008;133(1):264-70. 


\section{About the authors}

\section{Viviane Rossi Figueiredo}

Director. Department of Bronchoscopy, Instituto do Coração, Hospital das Clínicas da Faculdade de Medicina da Universidade de São Paulo - InCor/HC-FMUSP, Heart Institute/University of São Paulo School of Medicine Hospital das Clínicas - São Paulo, Brazil.

\section{Márcia Jacomelli}

Supervisor. Department of Bronchoscopy, Instituto do Coração, Hospital das Clínicas da Faculdade de Medicina da Universidade de São Paulo - InCor/HC-FMUSP, Heart Institute/University of São Paulo School of Medicine Hospital das Clínicas - São Paulo, Brazil.

\section{Ascédio José Rodrigues}

Attending Physician. Department of Bronchoscopy, Instituto do Coração, Hospital das Clínicas da Faculdade de Medicina da Universidade de São Paulo - InCor/HC-FMUSP, Heart Institute/University of São Paulo School of Medicine Hospital das Clínicas - São Paulo, Brazil.

\section{Mauro Canzian}

Physician. Anatomic Pathology Laboratory, Instituto do Coração, Hospital das Clínicas da Faculdade de Medicina da Universidade de São Paulo - InCor/HC-FMUSP, Heart Institute/University of São Paulo School of Medicine Hospital das Clínicas - São Paulo, Brazil.

\section{Paulo Francisco Guerreiro Cardoso}

Professor. Thoracic Surgery Section, Department of Cardiorespiratory Diseases, Instituto do Coração do Hospital das Clínicas da Faculdade de Medicina da Universidade de São Paulo (InCor-HCFMUSP, University of São Paulo School of Medicine Hospital das Clínicas Heart Institute), São Paulo, Brazil.

\section{Fábio Biscegli Jatene}

Full Professor. Thoracic Surgery Section, Department of Cardiorespiratory Diseases, Faculdade de Medicina da Universidade de São Paulo - FMUSP, University of São Paulo School of Medicine - São Paulo, Brazil. 